616-74 REGULACION DEL CALOR Y DEL ATRE EN IOS HORNOS ROTATORIOS IE VIA HUMEDA

(Wämewirtschaft und Luftfaktor des Zement-Nassdrehofens)

\title{
H. Eigen
}

De: "ZEMENT-ZAIK-GIPS", vol. 9, ne 9, septiembre 1956, peig. 403.

Si se desea conseguir una eveportoión intensa de? agre en un horno muy corto de via huimda, provisto de precalontadores y de secadores, el punto de rocio no debe encontronso por oncina de $73^{\circ} \mathrm{C}$. Por consiguiente, el horno de vía húmeda debe trebjjer con trr exceso de aire, tanto mayor cuanto menor see la cantidad de calor introducida por $\mathrm{kg}$ de clinker.

El aumento del excoso de sire $y$ el descenso del punto d: rocio quedan limitados por la terpencitura de la llama on la zona dc: cocción. Cuanto mayor es el diámétro del horno, ea decir, cuanto me yor es el consumo horario de carboin, tanto más se puede elevar el exceso de aire.

La condición necesaria para lograr un buen rendimiento téxmico en el horno rotatorio do vía líudeda, es oue los gases do es cape no entren en la zona de secado a una terperatura demasiado ba ja. Por este motivo, la parte del horno, on la cual las mateicias primas se calientan por encima de $120^{\circ} \mathrm{C}$, no cebe estar provista do accesorios internos.

Mediante una construcción spropiada del horno rotato rio, una buena homogeneidad y una dosificación exacta del combusti ble y de la pasta, se puede reducir le pórdida do celor do los an- 
ses de escape a $120 \mathrm{Koal} / \mathrm{kg}$ de clinker. De este modo, se puede redu cir el consumo calorifico a $1.200 \mathrm{Kcal} / \mathrm{kg}$ de olinker (contenido en agua de la pasta, 37\%).

S. F. S. 